\title{
An in-process measurement method for repair of defective microstructures by using a fast tool servo with a force sensor
}

\author{
Yuan-Liu Chen a,b, Shu Wang a, Yuki Shimizu* a, So Ito a, Wei Gao a and Bing-Feng Ju b \\ a Department of Nanomechanics, Tohoku University, Sendai, 980-8579, Japan \\ b State Key Laboratory of Fluid Power Transmission and Control, Zhejiang University, \\ Hangzhou, 310027, China \\ *Phone \& Fax: +81-22-795-6950, E-mail: yuki.shimizu@ nano.mech.tohoku.ac.jp
}

\begin{abstract}
:
This paper presents an in-process measurement method, which is capable of conducting real-time position identification and on-machine profile characterization of micro-defects in defective microstructures by using a fast tool servo with a force sensor (FS-FTS) on an ultra-precision lathe. A real-time thrust force map is captured in the process of cutting the microstructures by the FS-FTS to indicate the cutting status with respect to the cutting tool position in the coordinate system of the lathe. Based on the thrust force map, the positions of the defects are identified in real time from the locations of the abnormal variations in the map associated with the occurrences of the defects. Characterization of the defects is then conducted by employing the force-controlled cutting tool as the measuring probe to measure the sectional profiles of the defective microstructures. The identified positions and the characterized profiles of the defects are then fed back to carry out the repair fabrication of the defective microstructures with an accurate tool path. Experiments of in-process detection and repair of the micro-defects in the microstructures over the outer surface of a roll mould were carried out to confirm the feasibility of the proposed method.
\end{abstract}

Keywords: In-process measurement, Micro-defect, Microstructure, Repair, Fast tool servo, Force sensor, Cutting force, Thrust force 


\section{Introduction}

As one of the microcutting technologies [1, 2], the fast tool servo (FTS) [3, 4] is employed on an ultra-precision lathe to manufacture complex microstructured surfaces, such as micro-prisms [5], microlenses [6], microlens arrays [7, 8], sinusoidal grids [9], compound eye freeform surfaces [10], and diffractive optical elements (DOEs) $[11,12]$. It is expected to play an important role in fabrication of large-sized master moulds with microstructures, such as roll moulds or wafer-level moulds, for mass replication of surfaces with optical functions [13]. The fabricated microstructured surface of such a master mould is required to have a sub-micrometric form accuracy and an optical surface quality with zero or minimum defects $[14,15]$.

Meanwhile, the FTS-based microcutting is a complicated process in which material is removed at a high rate by a single-point diamond tool with a very sharp edge [16]. Although the advanced FTS systems and the ultra-precision lathes have been well developed to achieve sub-micrometric or even better positioning accuracies, the cutting process is affected by a number of factors in mechanical, thermal and chemical aspects [17]. Defects such as burrs, voids or bumps can be caused by tool-chip adhesion, tool chatter, tool wear, etc. [18, 19], especially when microstructures are cut on hard materials. Improper setting of cutting parameters such as cutting fluid mist can also lead to the formation of defects. The fabrication of a large-sized master mould is a very time-consuming process, which can last for a couple of days. It is difficult to maintain a constant cutting status throughout the process. There is thus a high possibility for micro-defects to occur in the midst of the process [20]. A post-process inspection of micro-defects on the master mould surface is carried out as the quality assurance test. However, there have been no ways to repair the micro-defects, although it is desired from the point of view of the extremely high cost of the master mould.

On the other hand, repair of micro-defects on photolithographic masks is a common process in semiconductor industry. The repair is typically carried out by using an electron beam (EB) [21]. In an EB repair process, a high-energy scanning electron beam in an EB equipment is employed to 
induce a local chemical reaction on the defective region of the mask surface [21]. Before the repair, the position and the profile of the defect on the mask are detected through scanning the same electron beam with a low energy setting over the entire wafer surface in the EB equipment. Because the same electron beam is used as the measuring probe for the detection and as the tool for the repair, the coordinates of the measuring probe are identical to those of the fabricating tool, resulting in an accurate repair of the defects.

The motivation of this research is to realize the repair of a micro-defect in a defective microstructure of the large-sized master mould fabricated by FTS on an ultra-precision lathe. As can be seen from the above case of photolithographic mask repair, it is necessary to develop a measurement technology that can address the next two important issues. The first issue is the detection of position and profile of the micro-defect over the entire surface of the mould in a short time. The second issue is the feedback of the measured information to the FTS on the ultra-precision lathe for generating an accurate repair cutting path. The measurement technology is thus required to have a high measurement speed and sub-micrometric resolutions in both vertical and lateral directions. The coordinate systems for the measurement and the repair cutting are also needed to have sub-micrometric correlations with each other so that the repair cutting can be made exactly against the micro-defect without influencing other parts of the mould surface. There are surface metrology-based methods existing for detection of the positions and profiles of defects on ultra-precision surfaces, such as the laser scattering method [22], interferometers [23], scanning probe microscopes (SPM) [24, 25], confocal microscopes [26], contact thermal sensors [27] or optical sensors [28]. Some of them with special designs can be set up on an ultra-precision lathe for on-machine measurement. However, the field of view of such a measuring instrument is very small, typically less than $1 \mathrm{~mm}$ square, for getting a sub-micrometric lateral resolution. This makes the micro-defect detection process on a large-sized master mould, typically with an area over $100 \mathrm{~mm}$ square, extremely time-consuming. It is also a difficult task to make sub-micrometric correlation of the coordinate system of the measuring system with that of the FTS on the ultra-precision lathe. 
Various sensors have been employed to monitor the cutting process [29, 30]. Among the measurable process variables, the cutting force is a good indicator of the cutting status and an important physical parameter for understanding the cutting phenomena [31, 32]. The formation of a defect, which causes a variation in the cutting force, can be detected in real time by making in-process force measurement with a direct linkage to the machine coordinate system [33]. Taking into consideration the small amplitude of the cutting force in the FTS-based microcutting, it is desired to set the location of a sensitive and stiff force sensor to the cutting point as close as possible. This has been achieved in a force-sensor integrated FTS developed by the authors, which is referred to as the FS-FTS [34]. It has also been demonstrated that the FS-FTS has the ability of making profile measurement of the machined surface by using the cutting tool as the measuring probe [35]. It is expected to utilize this function for characterization of the surface profile of the micro-defect on the master mould.

In this paper, a new in-process measurement method for the purpose of repairing defective microstructures on an ultra-precision lathe is proposed based on the abilities of the FS-FTS for real-time cutting force measurement and on-machine profile measurement. Experiments of in-process measurement and repair of micro-defects with dimensions on the order of 1 micrometer on a roll mould are carried out. The principle of the proposed method and the experimental results are presented.

\section{Principle}

There are two parts in the process of measurement and repair of defective microstructure elements. The first part, which is composed of two steps (Steps 1 and 2) shown in Fig. 1, is related to the in-process measurement method. The second part, which is also composed of two steps (Steps 3 and 4) shown in Fig. 2, is related to the repair process.

As can be seen in Fig. 1(a), the FS-FTS is mounted on a three-axis ultra-precision lathe for in-process measurement and repair of micro-defects on a roll mould. The roll mould is a cylindrical 
workpiece on which microstructure elements are fabricated by the FS-FTS. The workpiece is vacuum-chucked on the $C$-axis spindle with its rotation about the $Z$-axis. A $C$-rotary encoder is equipped with the spindle for rotational positioning. The $C$-axis spindle can be moved along the $Z$-axis by the Z-slide. The FS-FTS, with a piezoelectric-type force sensor integrated with the tool holder, is mounted on an $X$-slide to generate the fast in-feed motion of the tool along the $X$-direction. The position of the $X$-side and the $Z$-slide are measured by the $X$-linear encoder and the $Z$-linear encoder, respectively. During the cutting, the fast in-feed motion of the tool is generated by the FS-FTS in responding to the output pulse of the $C$-rotary encoder, in this case the tool servo motion with the $C$-directional rotation of the $C$-axis spindle can be synchronized. By combining the $X$-directional fast in-feed motion, the $Z$-directional cross-feed motion controlled by the $Z$-slide and the $C$-directional cutting motion generated by the spindle, microstructure elements are plunge cut with arrangement in columns on the outer surface of the roll mould [8]. For clarity, only five columns of micro-structures are shown in the figure. The depth of cut is controlled by the FS-FTS, and the profiles of the cut microstructure elements along the $C$-direction are determined by the programmed cutting path. An optical microscope is mounted on the lathe for imaging the cut microstructure elements in the experiments.

Step 1 shown in Fig. 1(a) is for real-time detection of the positions of defective microstructure elements. During the cutting, the $X$-directional thrust force is in-process measured by the force sensor of the FS-FTS. The output of the force sensor is monitored by a PC via an AD module in responding to the triggering signals from the output of the $C$-rotary encoder, by which the measurement of thrust force can be synchronized with the cutting process. At the same time, the Zand $C$-directional coordinates of the cutting point or the cutting tool measured by the Z-linear encoder and the $C$-rotary encoder are recorded by the PC via a DIO module. A thrust force map, in which the thrust forces are plotted in the $Z C$-coordinate system of the lathe, is captured to indicate the cutting status at each cutting point with respect to the $Z C$-coordinates of the cutting tool on the outer surface of the roll mould. Assume that two defective microstructure elements occur in the 
midst of fabrication of the 4th column microstructures due to an unexpected abnormal cutting condition. As a result, abnormal variations correspondingly arise in the monitored thrust forces which indicate the interaction status between the tool and the workpiece. In this case, based on the observation of the thrust force map, the positions of the defective microstructure elements in the $Z C$-coordinate system of the lathe can be identified in real time from those of the abnormal variations in the thrust force map.

The second step (Step 2) of the in-process measurement method is for characterizing the surface profiles of the defective microstructure elements based on the identified positions in Step 1. The measured surface profiles of the defective microstructure elements in Step 2 will be used as the criterion for determining if the defective elements are reparable or not in terms of the defect size and shape. Because cutting is a material removal process, the repair will be difficult if the size of the defect is larger than that of the designed microstructure element. If the defective elements are judged to be reparable, the measured information will be employed for generating the repair cutting path in the next step (Step 3). Fig. 1(b) shows a schematic of Step 2. Instead of using an additional profile measuring instrument, the cutting tool itself is employed as a force-controlled stylus probe to measure the sectional profiles of the defective microstructure elements. As shown in Fig. 2, the cutting tool is first brought to the identified locations of the defective elements among the 4th column by controlling the slides and the spindle based on the $Z C$-coordinates of the defective microstructure elements. Then the workpiece is rotated by the spindle so that the cutting tool can scan the defective elements along the $C$-direction for surface profile measurement. In the scanning, the force sensor of the FS-FTS is employed to detect the contact force between the tool tip and the workpiece surface. A force feedback control loop is applied to the FS-FTS for controlling the Z-directional position of the cutting tool so that the tool tip can track the surface profile with a constant contact force. The scan position along the $C$-direction is measured by the $C$-rotary encoder, and the $X$-directional tracking displacement of the tool is measured by the displacement sensor of the FS-FTS, from which the sectional profiles of the defective microstructure elements can be 
obtained.

Fig. 2 (a) shows a schematic of the third step (Step 3) for repairing the defective microstructure elements. The two defective microstructure elements among the 4th column are re-cut by applying a programmed cutting path according to the measurement results in the previous steps and the designed profiles of the microstructure elements. Since all the information is in the same coordinate system of the FS-FTS and the ultra-precision lathe, the repair operation can be carried out accurately. Finally, to evaluate the repaired results (Step 4), the force-controlled tool is brought once more to measure the sectional profile of the repaired microstructure elements as shown in Fig. 2 (b). The repair operation can be repeated until the repaired microstructures reach the required accuracy.

\section{Experiments}

An experimental system was set up as shown in Fig. 3. The maximum travel range of the $X$-slide and the $Z$-slide was $150 \mathrm{~mm}$ and $220 \mathrm{~mm}$, respectively. Both the $X$-linear encoder and $Z$-linear encoder had a resolution of $10 \mathrm{~nm}$. The $C$-encoder of the spindle had an output of 180, 000 pulses per revolution. A Ni-P plated roll mould with a diameter of $55 \mathrm{~mm}$ was mounted on the $C$-axis spindle of the lathe. The stroke and resolution of the FS-FTS were $45 \mu \mathrm{m}$ and $1 \mathrm{~nm}$, respectively. A piezoelectric force sensor with a stiffness of $953.30 \mathrm{~N} / \mu \mathrm{m}$ was integrated with the tool holder for the measurement of thrust force in the cutting process and contact force in the profile characterization process. An optical microscope with optical zoom ranging from $\times 75$ to $\times 750$ was also mounted on the lathe for observation of the microstructures.

The sensitivity of the FS-FTS for measurement of the thrust force was calibrated by using a series of known weights as the input forces. The weight was hung on the tool holder of the FS-FTS via a pulley. The weight was quickly lifted up to release the force applied to the force sensor and the change in the force sensor output was monitored. Fig. 4 shows the output of the force sensor with respect to the applied force. The sensitivity of the force sensor was evaluated to be $241 \mathrm{mV} / \mathrm{N}$. The peak-to-valley amplitude of the linearity error of the force sensor output was evaluated to be $3.8 \mathrm{mV}$, 
corresponding to $0.016 \mathrm{~N}$.

After the calibration, the FS-FTS was then employed to measure the thrust force in the cutting process. A round nose diamond tool with a nominal nose radius of $100 \mu \mathrm{m}$, a rake angle of $0^{\circ}$ and a clearance angle of $7^{\circ}$ was mounted in the tool holder of the FS-FTS to make plunge cut of a microstructure element on the roll mould surface. The depth of cut and the length of the microstructure element were $3.0 \mu \mathrm{m}$ and $100 \mu \mathrm{m}$, respectively. During the cutting, the output of the force sensor was monitored. Due to the existing masses of the force sensor, the tool holder and the tool, the inertial force was definitely included in the output of the force sensor. To accurately obtain the thrust force, the inertial force was measured independently by controlling the FS-FTS to generate the same displacement but without the actual cutting operation. At first, the output of the force sensor was detected. The force output data was then evaluated by calculating the difference between the force sensor output measured under the cutting condition and the inertial force measured without actual cutting operation. Fig. 5 shows the measurement result of the thrust force. The amplitude of the thrust force was evaluated to be approximately $0.28 \mathrm{~N}$. The force sensor was confirmed to be sensitive enough for measurement of thrust force during the cutting of microstructures. Thus, such a thrust force measurement procedure was adopted for all the following experiments.

On the other hand, when conducting profile characterization by using the cutting tool as a measuring probe, a small contact force in the order of sub- $\mathrm{mN}$ was required to reduce the damage to the workpiece surface. To increase the sensitivity of the FS-FTS for measuring small contact forces, a modulation method was employed. Fig. 6 shows a diagram of the modulation method to increase the sensitivity of the force measurement. By applying a sinusoidal voltage from a function generator to the actuator of the FT-FTS, the tool was oscillated at a constant frequency of $220 \mathrm{~Hz}$ with an amplitude of 5 nanometers along the $X$-direction. To test the sensitivity of the FS-FTS for contact force measurement, the tool was brought to make contact with the workpiece surface by controlling the $X$-slide. When the tool was made to contact with the workpiece surface, the resultant contact 
force was accurately detected in the presence of electronic noise by a lock-in amplifier. Fig. 7 shows the results. The detected contact force was plotted in a relative scale since it was the result filtered by the lock-in amplifier. The amplitude and frequency of the tool oscillation were $5 \mathrm{~nm}$ and $220 \mathrm{~Hz}$, respectively. The amplitudes of the contact forces at contact displacements from $10 \mathrm{~nm}$ to $50 \mathrm{~nm}$ were evaluated to be $0.1 \mathrm{mN}, 0.3 \mathrm{mN}, 0.55 \mathrm{mN}, 0.85 \mathrm{mN}$ and $1.20 \mathrm{mN}$, respectively. To reduce the surface damage caused by the scanning of the tool across the workpiece surface for characterization of the defective microstructures, the contact force was set to be $0.1 \mathrm{mN}$ in the following experiments.

Experiments of detection and repair of a single defective microstructure element were carried out. By using a diamond tool with a nose radius of $200 \mu \mathrm{m}$, a plunge cut was made to generate a microstructure element on the roll mould surface. The depth of cut and the length of the microstructure element were $5.0 \mu \mathrm{m}$ and $200 \mu \mathrm{m}$, respectively. The spindle speed was set to be 5 rpm. A defect was set at the end of the microstructure element by programming the cutting path. Fig. 8 shows the optical microscopic image of the defective microstructure element and the measured thrust force during the cutting. It can be seen that the defect was well indicated from the variation in the measured thrust force.

The tool was then brought to repair the defective microstructure element. Four repeated repairs were carried out. Fig. 9 shows the measured thrust force during the repair process. In the repair, the tool was controlled to re-cut the defect area of the defective element. At the first repair, the thrust force at the defect area shown in Fig. 8 had a sudden increase due to the uncut residual. The amplitude of the thrust force of the first time repair was evaluated to be $0.65 \mathrm{~N}$. With the decrease of the uncut depth, the amplitudes of the thrust forces at the subsequent repairs were reduced to be $0.16 \mathrm{~N}, 0.07 \mathrm{~N}$ and $0.03 \mathrm{~N}$, respectively. Fig. 10 (a) shows an optical microscopic image of the microstructure element after the fourth time repair. A good shape of the repaired microstructure element can be observed from the figure. As for comparison, another defective microstructure element with only one time repair was shown in Fig. 10 (b). A residual part of the defect can be 
observed from the optical microscopic image. It was due to the deflection of the FS-FTS caused by the large impact force when the tool contacted with the defect. In the following experiments, the multi-time repair strategy was thus adopted. The repair was repeated until a low thrust force was achieved. It should be noted that a gradual increase of the cutting depth is effective for avoiding chipping on the workpiece surface when a multi-time repair strategy is applied to the repair of uncut defects as shown in Fig. 8.

Experiments were carried out on a microstructure element array, in which the locations of the defective microstructure elements were also identified. Fig. 11 shows an optical microscopic image of a part of the microstructure element array arranged in columns which was cut by using a diamond tool with a nose radius of $100 \mu \mathrm{m}$. The depth of cut and the length of the microstructure element were set to be $3.0 \mu \mathrm{m}$ and $100 \mu \mathrm{m}$, respectively. The pitches along the $Z$ - and $C$-directions were set to be $80 \mu \mathrm{m}$ and $150 \mu \mathrm{m}$, respectively. For clarity, only 4 columns are shown in the figure. There were more than one thousand microstructure elements cut in a column along the circumference of the roll mould. Due to the limited field of view of the optical microscope, only several microstructure elements were shown in a column in the optical microscopic image. Two defective microstructure elements were intentionally generated among the normal elements in Column 2 by programming the tool path. For clarity, the microstructure elements in each column were numbered as shown in the figure.

Fig. 12 shows a part of the in-process measured thrust forces map, in which the thrust force at each cutting point was plotted with respect to the $Z$ - and $C$-directional coordinates measured by the $Z$-linear encoder and $C$-rotary encoder, respectively. The mean amplitude of the thrust force was evaluated to be $0.29 \mathrm{~N}$. From the thrust force map, it can be seen that there were abnormal variations occurred at the 2 nd and the 3 rd microstructure elements in Column 2, which were correspondent to the appearance of defective microstructure elements. The thrust forces measured when cutting normal and defective microstructure elements are compared in Fig. 13. The difference of the amplitudes at the micro-defect areas was evaluated to be approximately $0.2 \mathrm{~N}$. 
To characterize the profiles of the micro-defects, the $C$-directional sectional profiles of the two defective microstructure elements were measured by employing the tool as a force-controlled measuring stylus probe. The speed of the scanning, generated by the spindle, was set to be 0.001 degree/s. For comparison, the sectional profiles of the normal microstructure elements were also measured. Fig. 14 shows the characterization results. The peak-to-valley difference between the measured profile of the defective microstructure element and that of the normal microstructure element at the micro-defect area, which was recognized as the profile deviation, was evaluated to be approximately $0.55 \mu \mathrm{m}$. In addition, the developed system was verified to have a measurement resolution of approximately $0.1 \mu \mathrm{m}$ based on the repeatability of the profile measurement.

Based on the identified position and the characterized profile, repair of the defective microstructure elements was carried out by programming a repair cutting path. In the repair, the spindle speed was set to be $5 \mathrm{rpm}$, which was the same as that in the previous cutting operation. Fig. 15 shows the monitored thrust force during the repair process. Two repeated repairs were carried out. The thrust force amplitudes at the area of the micro-defect were evaluated to be approximately $0.1 \mathrm{~N}$ in the first repair and $0.03 \mathrm{~N}$ in the second repair, respectively. Fig. 16 shows an optical microscopic image of the microstructure element array after the repair. It can be seen that the defective microstructure elements were well repaired. To further evaluate the repair effect quantitatively, the $C$-directional sectional profile of the repaired microstructure element was measured by the force-controlled tool. The scanning speed was set to be 0.001 degree/s. Fig. 17 shows the measured profile of the repaired microstructure element. The previously measured defective profile and the profile of a normal microstructure element are also shown in the figure. It can be seen that the profile of the repaired microstructure element agreed well with that of the normal microstructure element. The profile deviations at the micro-defect area before and after the repair were compared in Fig. 18. It can be seen that the profile deviation of the defective microstructure element was reduced from $0.55 \mu \mathrm{m}$ to $0.08 \mu \mathrm{m}$ by the repair. The whole procedure of the detection, identification, repairing of a defect and verification of the repaired result can be 
carried out within 10 minutes. In this paper, profile measurement and repairing of defects fabricated by a programmed tool path were carried out as the first step of the feasibility study on the proposed concept. In practice, many types of defects can be generated on the workpiece surface. Further applications of the proposed method to different types of defects will be investigated in the future work. It should also be noted that an intensive research should be carried out to investigate the damages on the workpiece surface caused by the tool when the tool is employed as the force-controlled measuring stylus probe although no obvious damages on the workpiece surface were identified in the experiments reported in this paper.

\section{Conclusions}

An in-process measurement method has been developed for repair of defective microstructures by using a force sensor integrated fast tool servo (FS-FTS) on an ultra-precision lathe. A thrust force map is captured in real time to monitor the cutting status at each cutting position. The thrust forces measured by the piezoelectric force sensor of the FS-FTS are plotted in the map with respect to the coordinates of the cutting positions measured by the linear encoder of the slide and the rotary encoder of the spindle. The occurrence and the position of the defective microstructure element could be detected from the abnormal variation signal in the thrust force map. Moreover, the sectional profile of the defective microstructures could also be characterized by using the tool itself as a force-controlled stylus probe. Based on the results of position identification and profile characterization, an accurate repair of the micro-defect could be thus realized.

In experiments, the performances of FS-FTS for force measurement, including the thrust force measurement for conducting plunge cutting of microstructures and the contact force measurement for conducting profile characterization, were investigated. Then a microstructure array with defective elements, in which the dimensions of the micro-defects were on the order of 1 micrometer, was cut over the outer surface of a Ni-P plated roll mould with a diameter of $55 \mathrm{~mm}$. By using the proposed in-process measurement method, the position and sectional profile of the defective 
microstructures elements were indentified and characterized, respectively. Based on the measurement result, repair of the defective microstructure elements was successfully carried out. The measured profile deviation of the defective microstructure element was reduced from $0.55 \mu \mathrm{m}$ to $0.08 \mu \mathrm{m}$ by the repair. Feasibility of the proposed method was confirmed by the experimental results.

\section{Acknowledgements}

This research is supported by JST and JSPS. Y. L. Chen appreciates the Scholarship Award for Excellent Doctoral Student granted by the Ministry of Education and the support from China Scholarship Council.

\section{References}

[1] Alting L, Kimura F, Hansen H-N and Bissacco G. Micro Engineering. CIRP Annals Manufacturing Technology 2003;52(2):635-57.

[2] Masuzawa T. State of the art of micromachining. CIRP Annals - Manufacturing Technology 2000;49(2):473-88.

[3] Patterson S-R and Magrab E-B. Design and testing of a fast tool servo for diamond turning. Precision Engineering 1985;7(3):123-28.

[4] Woronko A, Huang J and Altintas Y. Piezoelectric tool actuator for precision machining on conventional CNC turning centers. Precision Engineering 2003;27(4):335-45.

[5] Brinksmeier E, Gläbe R and Schönemann L. Diamond micro chiseling of large-scale retroreflective arrays. Precision Engineering 2012;36(4):650-57.

[6] Ludwick S-J, Chargin D-A, Calzaretta J-A and Trumper D-L. Design of a rotary fast tool servo for ophthalmic lens fabrication. Precision Engineering 1999;23(4):253-59.

[7] Scheiding S, Yi A-Y, Gebhardt A, Li L, Risse S, Eberhardt R and Tünnermann A. Freeform manufacturing of a microoptical lens array on a steep curved substrate by use of a voice coil fast tool servo. Optical Express 2011;19(24):23938-51. 
[8] Noh Y-J, Arai Y, Tano M, Gao W. Fabrication of large-area micro-lens arrays with fast tool control. International Journal of Precision Engineering and Manufacturing 2008;9(4):32-38.

[9] Gao W, Araki T, Kiyono S, Okazaki Y and Yamanaka M. Precision nano-fabrication and evaluation of a large area sinusoidal grid surface for a surface encoder. Precision Engineering 2003;27(3):289-98.

[10] Fang F-Z, Zhang X-D, Weckenmann A, Zhang G-X and Evans C. Manufacturing and measurement of freeform optics. CIRP Annals - Manufacturing Technology 2013;62(2):823-46.

[11] Brinksmeier E, Riemer O, Gläbe R, Lünemann B, Kopylow C-V, Dankwart C and Meier A. Submicron functional surfaces generated by diamond machining. CIRP Annals Manufacturing Technology 2010;59(1):535-38.

[12] Zhou J, Li L, Naples N, Sun T and Yi A-Y. Fabrication of continuous diffractive optical elements using a fast tool servo diamond turning process. Journal of Micromechanics and Microengineering 2013;23(7):075010.

[13] Dumond J-J and Low H-Y. Recent developments and design challenges in continuous roller micro- and nanoimprinting. Journal of Vacuum Science and Technology B 2012;30(1):695-714.

[14] Bruzzone A-A, Costa H-L, Lonardo P-M and Lucca D-A. Advances in engineered surfaces for functional performance. CIRP Annals - Manufacturing Technology 2008;57(2):750-69.

[15] De Chiffre L, Kunzmann H, Peggs G-N and Lucca D-A. Surface in precision engineering, microengineering and nanotechnology. CIRP Annals - Manufacturing Technology 2003;52(2):561-77.

[16] Gao W, Motoki T and Kiyono S. Nanometer edge profile measurement of diamond cutting tools by atomic force microscope with optical alignment sensor. Precision Engineering 2006;30(4):396-405

[17] Chae J, Park S-S and Freiheit T. Investigation of micro-cutting operations. International 
Journal of Machine Tool and Manufacture 2006;46(3):313-32.

[18] Aurich J-C, Dornfeld D, Arrazola P-J, Franke V, Leitz L and Min S. Burrs - analysis, control and removal. CIRP Annals - Manufacturing Technology 2009;58(2):519-42.

[19] Kawasegi N, Niwata T, Morita N, Nishimura K and Sasaoka H. Improving machining performance of single-crystal diamond tools irradiated by a focused ion beam. Precision Engineering 2013;38(1):174-82.

[20] Oh J-S, Shim J-Y, Song C-K and Park C-H. Design and evaluation of ultra precision roll lathe for large-scale micro-structured optical films. Proceeding of the $10^{\text {th }}$ International Conference of the European Society for Precision Engineering and Nanotechnology. 2010. p. 287-91.

[21] Hau Riege S-P, Barty A, Mirkarimi P-B, Baker S, Coy M-A, Mita M, Robertson V-E, Liang T and Stivers A. Repair of phase defects in extreme-ultraviolet lithography mask blanks. Journal of applied physics 2004;96(11):6812-21.

[22] Takahashi S, Miyoshi T, Takaya Y and Saito Y. In-process measurement method for detection and discrimination of silicon wafer surface defects by laser scattered defect pattern. CIRP Annals - Manufacturing Technology 1998;47(1):459-62.

[23] Nomura T, Kamiya K, Miyashiro H, Okuda S, Tashiro H and Yoshikawa K. Shape measurements of mirror surfaces with a lateral-shearing interferometer during machine running. Precision Engineering 1998;22(4):185-89.

[24] Gao W, Aoki J, Ju B-F and Kiyono S. Surface profile measurement of a sinusoidal grid using an atomic force microscope on a diamond turning machine. Precision Engineering 2007;31(3):304-309.

[25] Chen Y-L, Zhu W-L, Y S, Ju B-F and G Y. Large-area profile measurement of sinusoidal freeform surfaces using a new prototype scanning tunneling microscopy. Precision Engineering 2014;38(2):414-20.

[26] Hansen H-N, Carneiro K, Haitjema H and De Chiffre L. Dimensional micro and nano metrology. CIRP Annals - Manufacturing Technology 2006;55(2):721-43. 
[27] Shimizu Y, Lu W, Ohba Y and Gao W. Feasibility study on the concept of thermal contact sensor for nanometre-level defect inspections on smooth surfaces. Measurement Science and Technology 2014. In Press.

[28] Uda Y, Kohno T and Yazawa Y. In-process measurement and workpiece-referred form accuracy control system (WORFAC): application to cylindrical turning using an ordinary lathe. Precision Engineering 1996;18(1):50-55.

[29] Teti R, Jemielniak K, Donnell G and Dornfeld D. Advanced monitoring of machining operations. CIRP Annals - Manufacturing Technology 2010;59(2):717-39.

[30] Marsh E-R, Moerlein A-W, Deakyne T-R-S and Van Doren M-J. In-process measurement of form error and force in cylindrical-plunge grinding. Precision Engineering 2008;32(4):348-52.

[31] Gao W, Hocken R-J, Patten J-A, Lovingood J and Lucca D-A. Construction and testing of a nanomachining instrument. Precision Engineering 2000;24:320-28.

[32] Gao W, Hocken R-J, Patten J-A and Lovingood J. Force measurement in a nanomachining instrument. Review of Scientific Instruments 2000;71(11):4325-29.

[33] Ding X, Jarfors A-E-W, Lim G-C, Shaw K-C, Liu Y-C and Tang L-J. A study of the cutting performance of poly-crystalline oxygen free copper with single crystalline diamond micro-tools. Precision Engineering 2012;36(1):141-52.

[34] Nor Y-J, Arai Y and Gao W. Improvement of a fast tool control unit for cutting force measurement in diamond turning of micro-lens array. International Journal of Surface Science and Engineering 2009;3(3):227-41.

[35] Lee K-W, Noh Y-J, Arai Y, Shimizu Y and Gao W. Precision measurement of micro-lens profile by using a force-controlled diamond cutting tool on an ultra-precision lathe. International Journal of Precision Technology 2011;2(2):211-25. 


\section{Figure captions}

Fig. 1. Steps of the in-process measurement method for repair of destructive microstructures on a roll mould.

(a) Step 1 for real-time detection of the micro-defect positions

(b) Step 2 for characterization of the micro-defect surface profiles

Fig. 2. The repair and evaluation steps.

(a) Step 3 for repairing the defective microstructure elements

(b) Step 4 for evaluating the repair results

Fig. 3. Photograph of the experimental setup on a three-axis precision lathe.

Fig. 4. Sensitivity calibration of the force sensor.

Fig. 5. Measurement of the thrust force.

Fig. 6. Method to increase the sensitivity when conducting profile measurement.

Fig. 7. Contact testing between the tool and the workpiece surface based on the increased sensitivity.

Fig. 8. Optical microscopic image of a defective microstructure elements and the measured corresponding thrust force.

Fig. 9. Measured thrust forces during the multi-time repair process.

Fig. 10. Optical microscopic images of the repaired results after (a) multi-time repair and (b) one-time repair.

Fig. 11. Optical microscopic image of a part of the cut microstructure element array.

Fig. 12. A part of the in-process monitored thrust force map during the cutting of the microstructure element array.

Fig. 13. Comparison of the thrust force during the fabrication of defective and normal microstructure elements.

Fig. 14. Measured sectional profile of the defective microstructure elements compared with the measured profile of normal elements.

Fig. 15. Measured thrust force during the repair process.

Fig. 16. Optical microscopic image of the microstructure element array after repair. 
Fig. 17. Measured sectional profile of the defective microstructure element after repair.

Fig. 18. Comparison of the measured profile deviation before and after repair. 


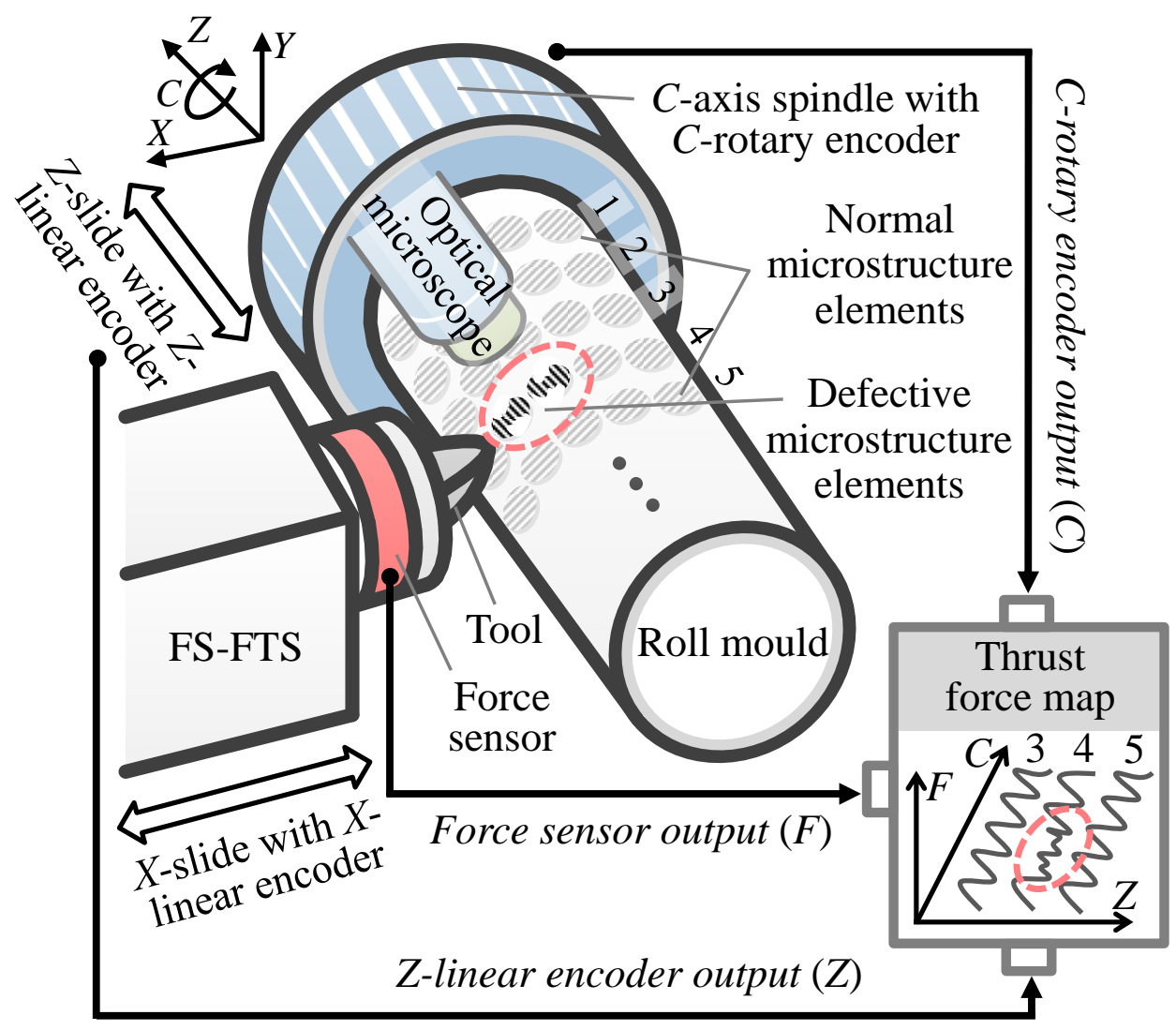

(a) Step 1 for real-time detection of the micro-defect positions

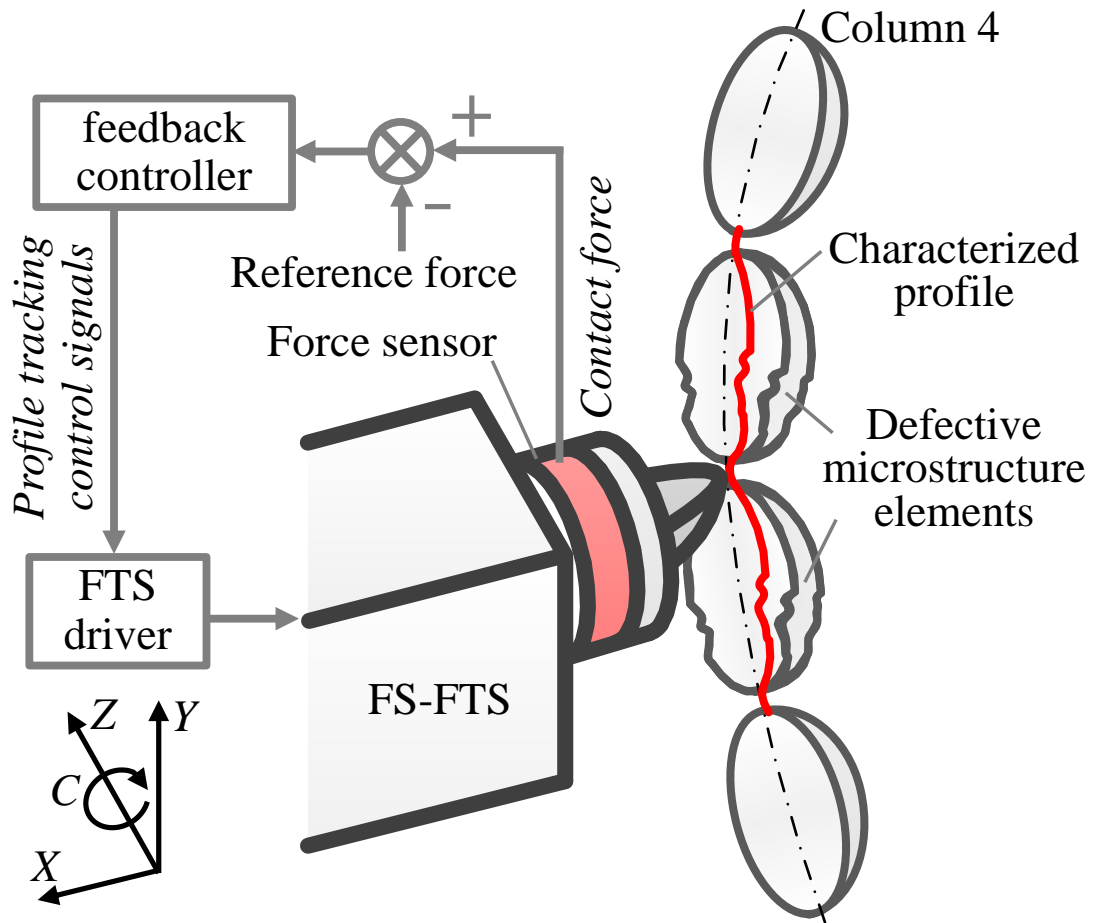

(b) Step 2 for characterization of the micro-defect surface profiles

Fig. 1. Steps of the in-process measurement method for repair of destructive microstructures on a roll mould. 


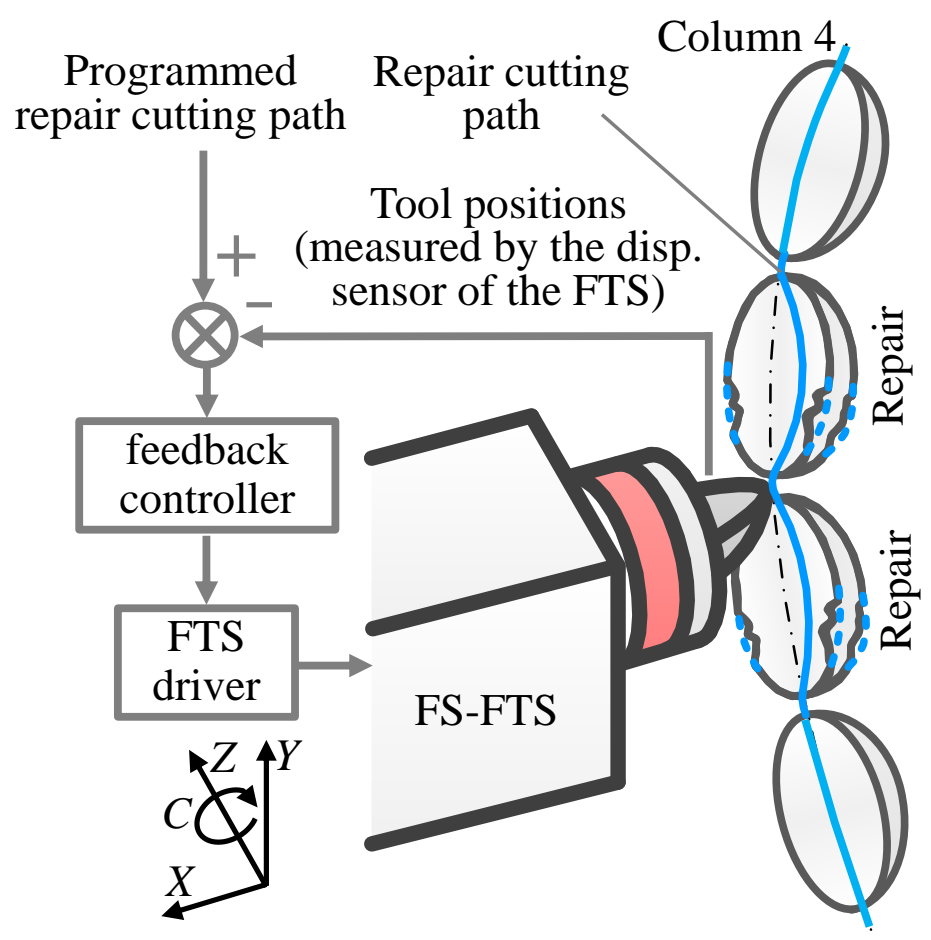

(a) Step 3 for repairing the defective microstructure elements

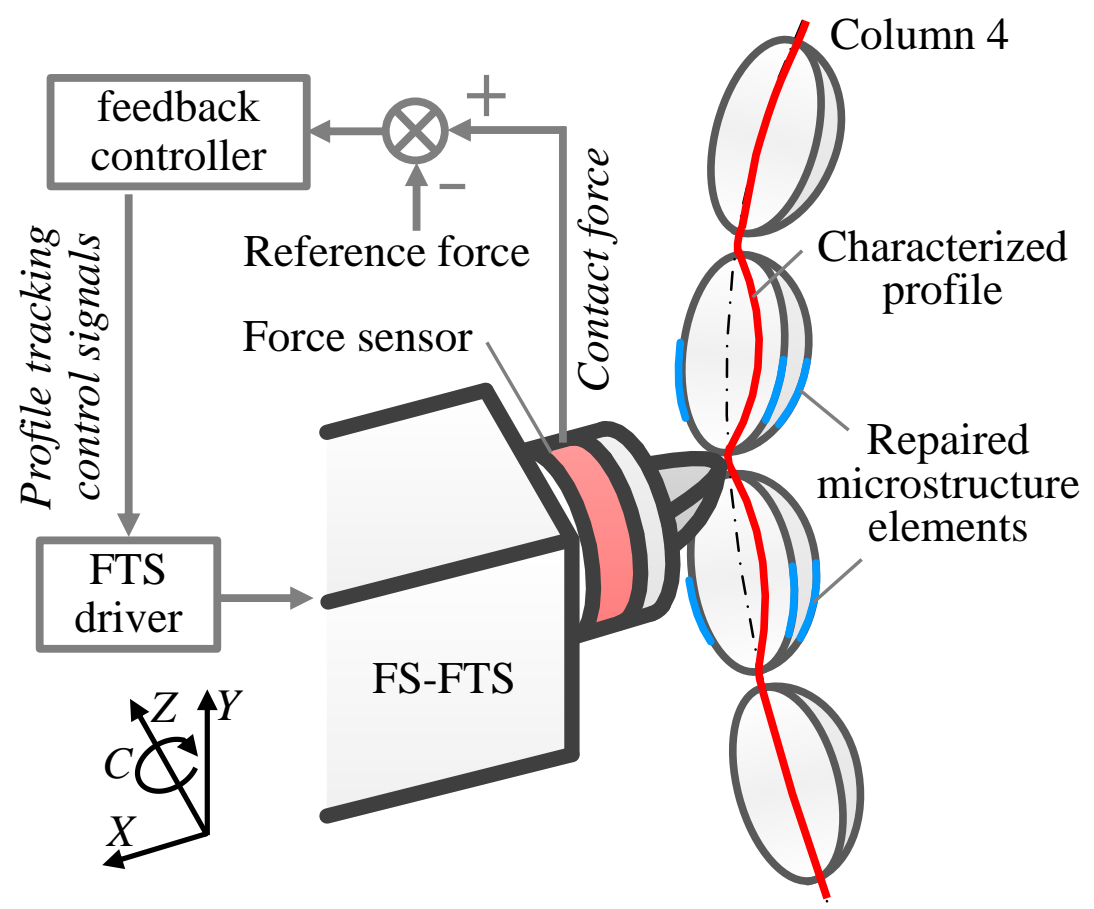

(b) Step 4 for evaluating the repair results

Fig. 2. The repair and evaluation steps. 


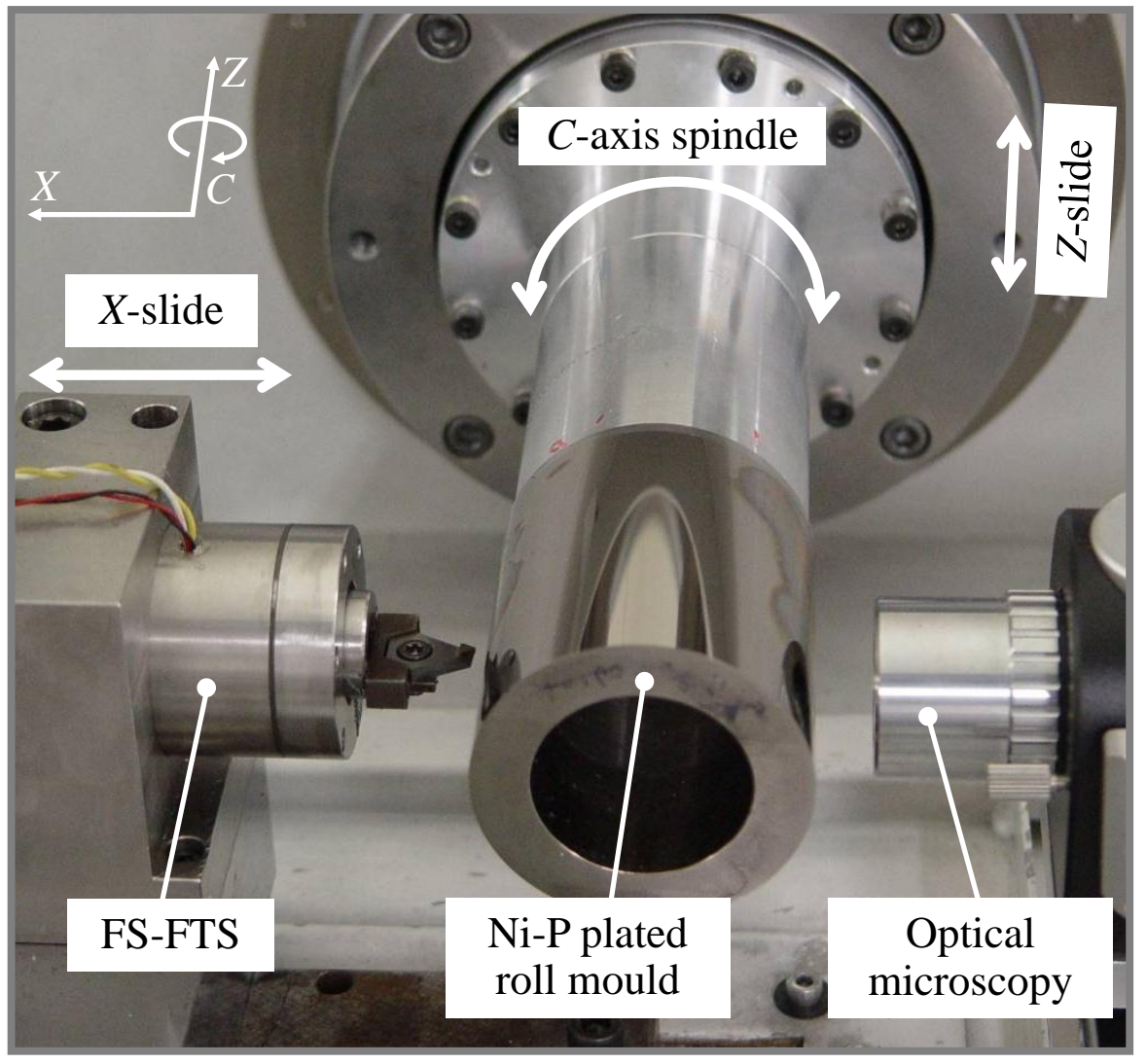

Fig. 3. Photograph of the experimental setup on a three-axis ultra-precision lathe. 


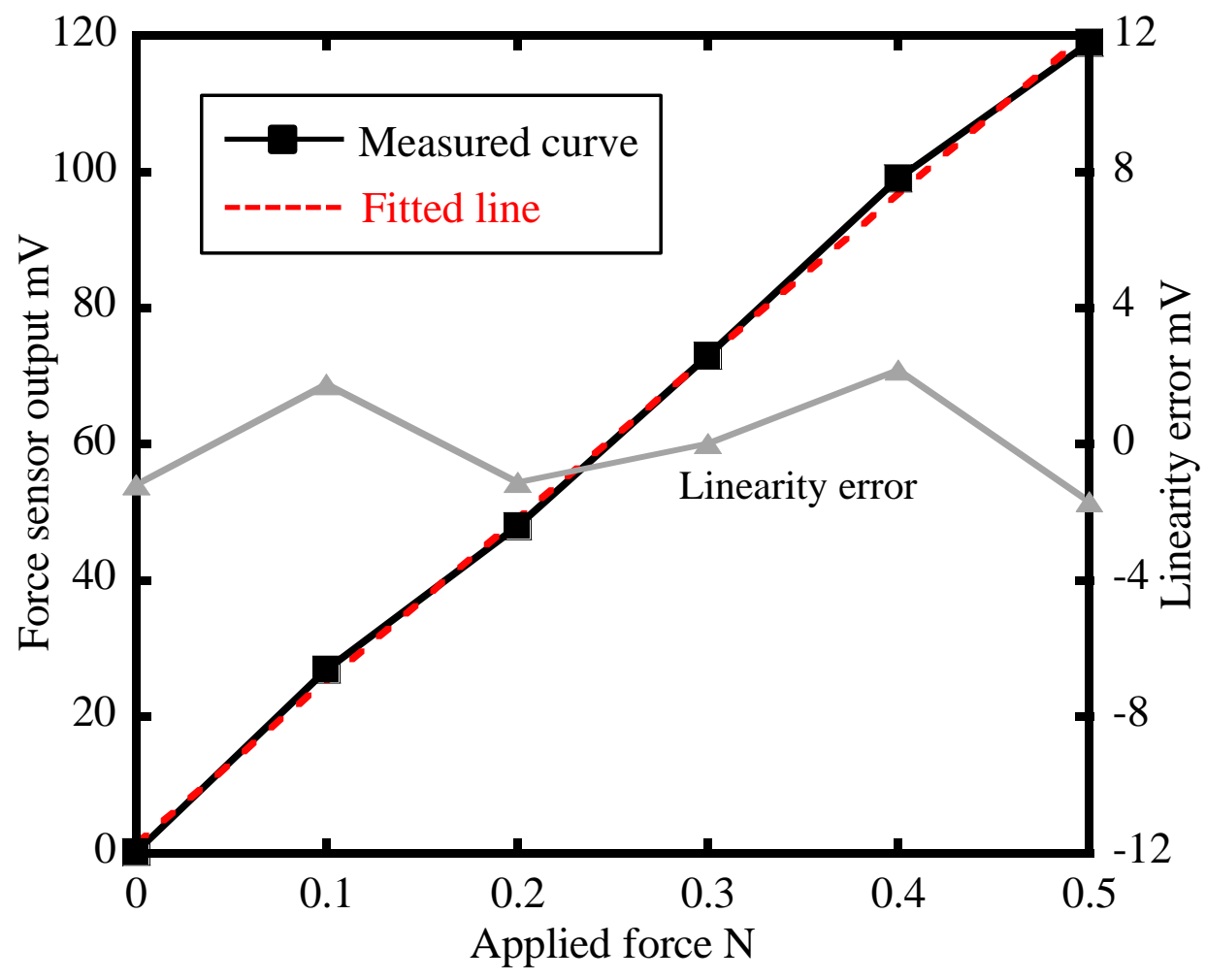

Fig. 4. Sensitivity calibration of the force sensor. 


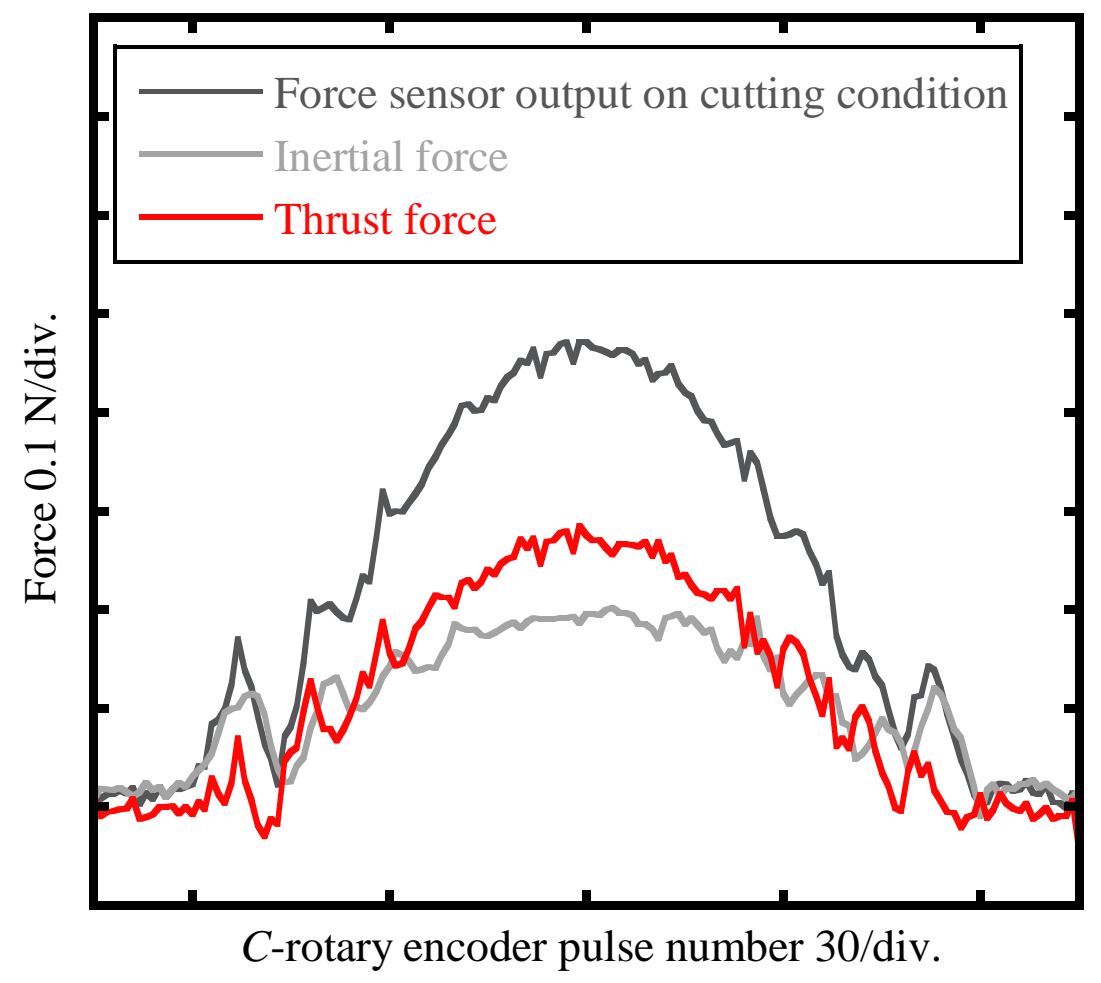

Fig. 5. Measurement of the thrust force. 


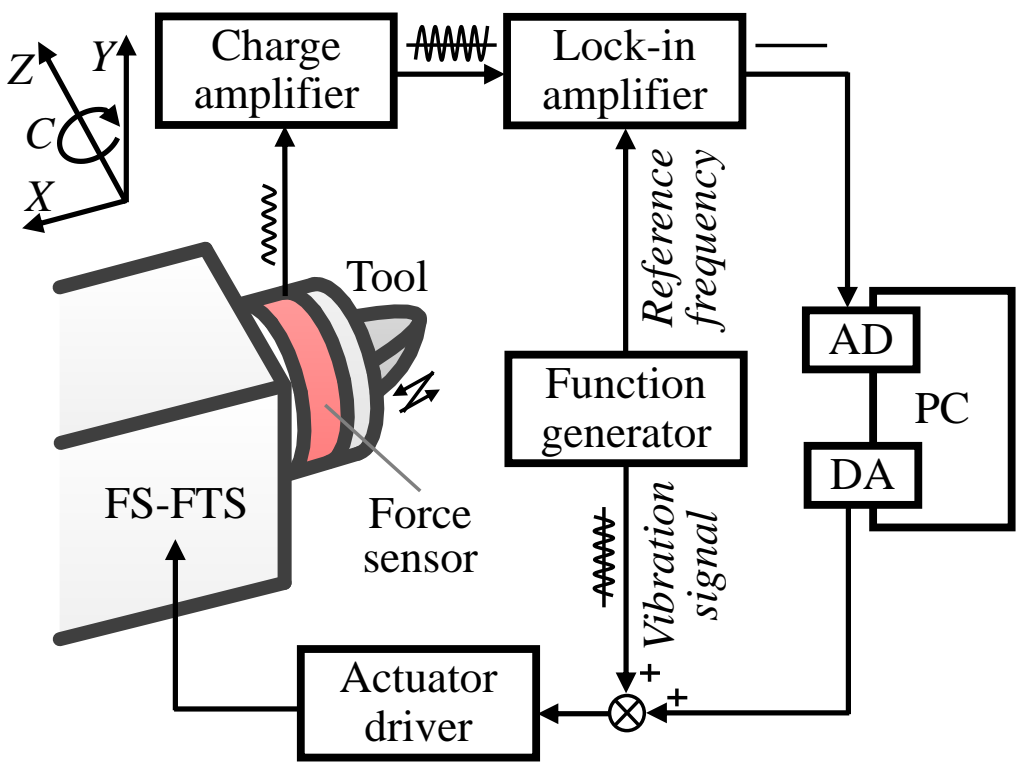

Fig. 6. Method to increase the sensitivity when conducting profile measurement. 


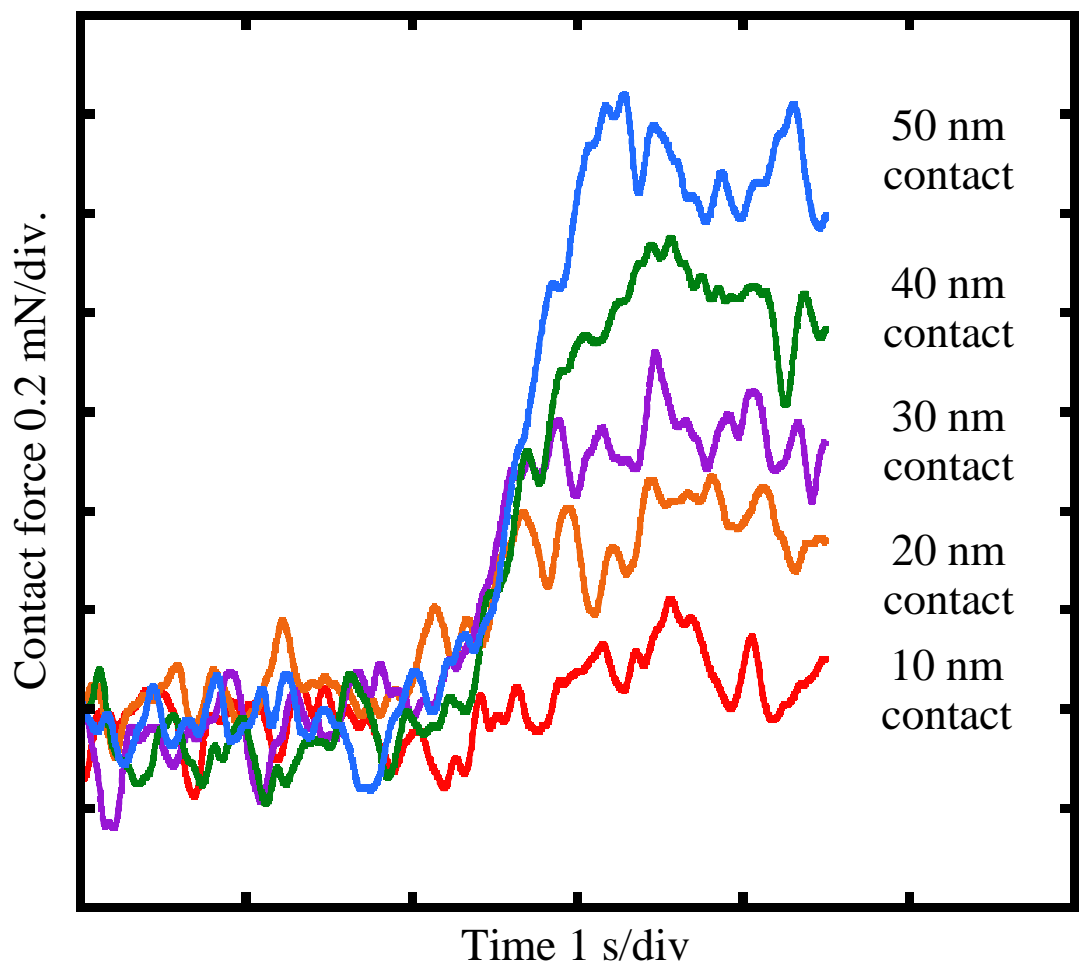

Fig. 7. Contact testing between the tool and the workpiece surface based on the increased sensitivity. 


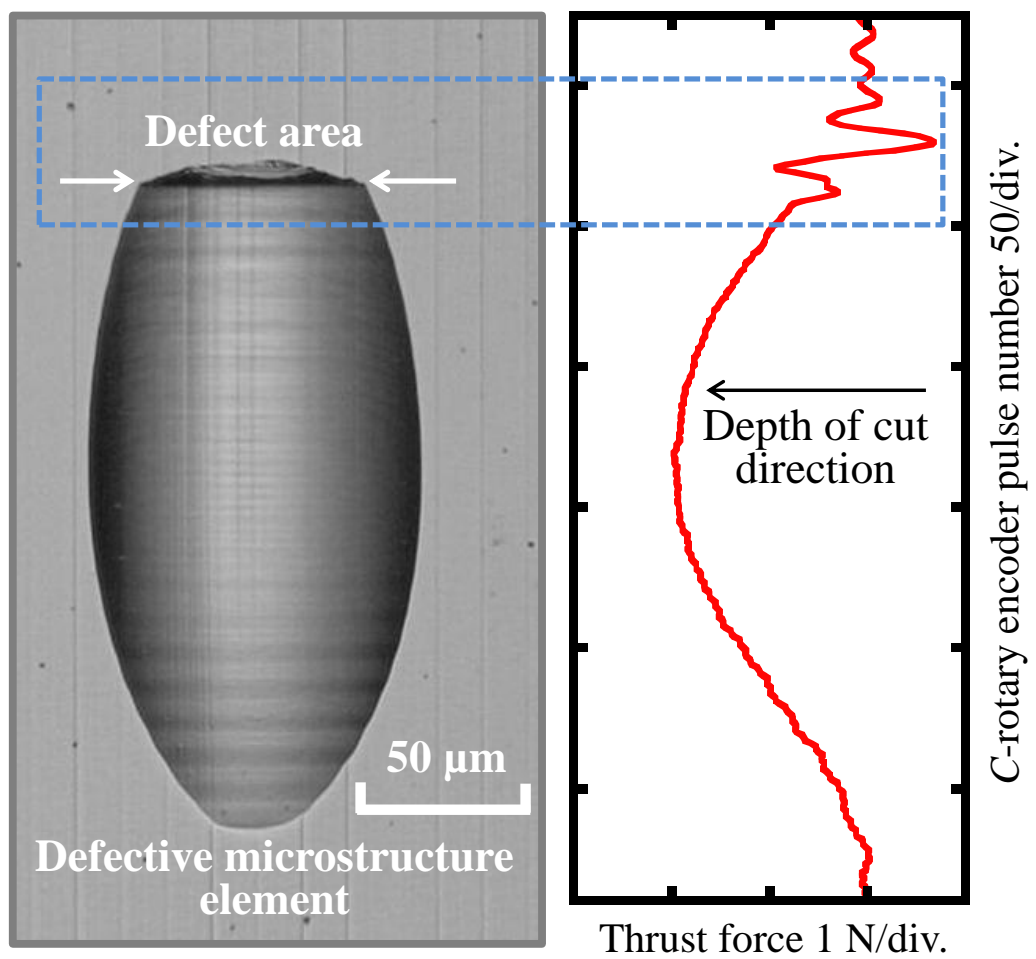

Fig. 8. Optical microscopic image of a defective microstructure elements and the measured corresponding thrust force. 


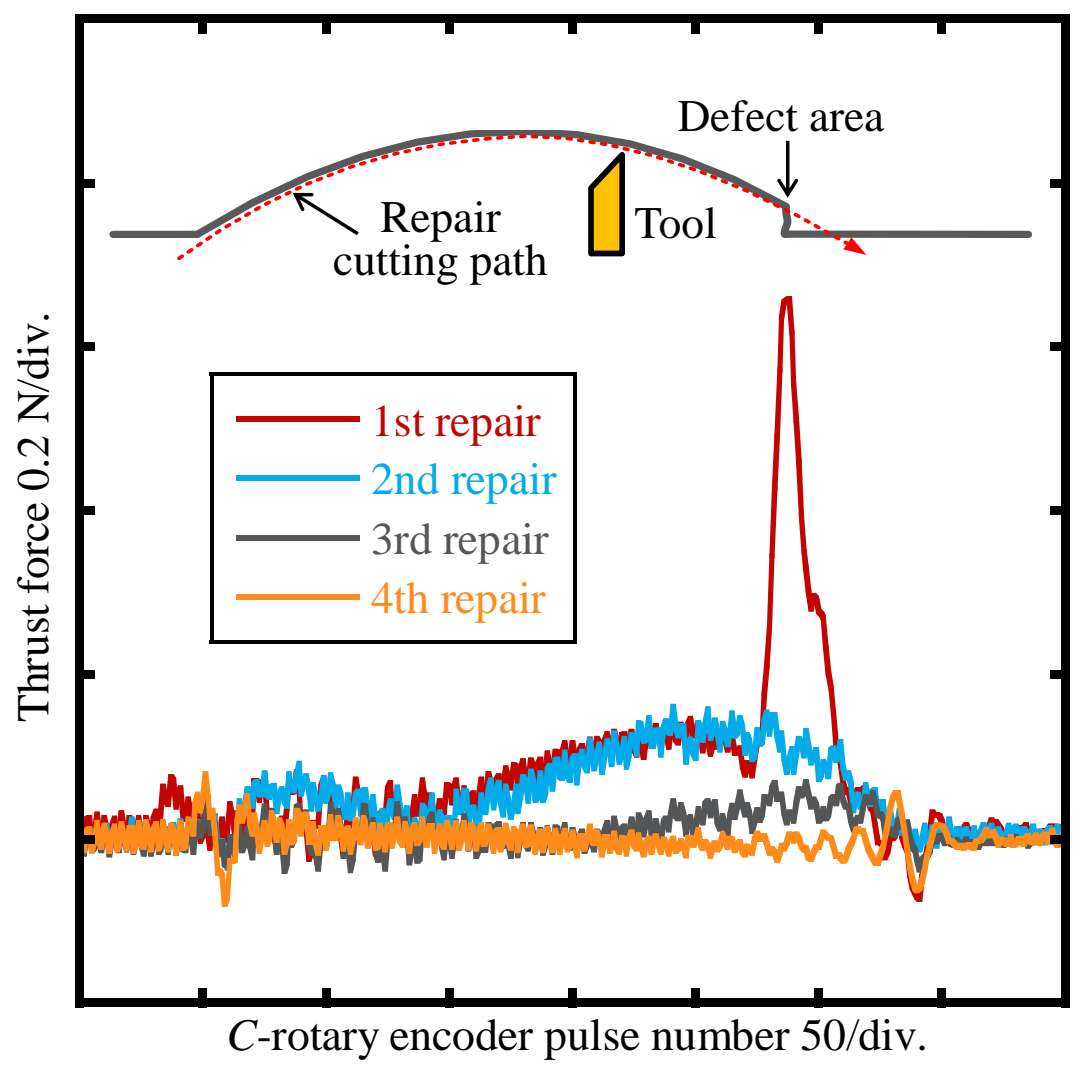

Fig. 9. Measured thrust forces during the multi-time repair process. 


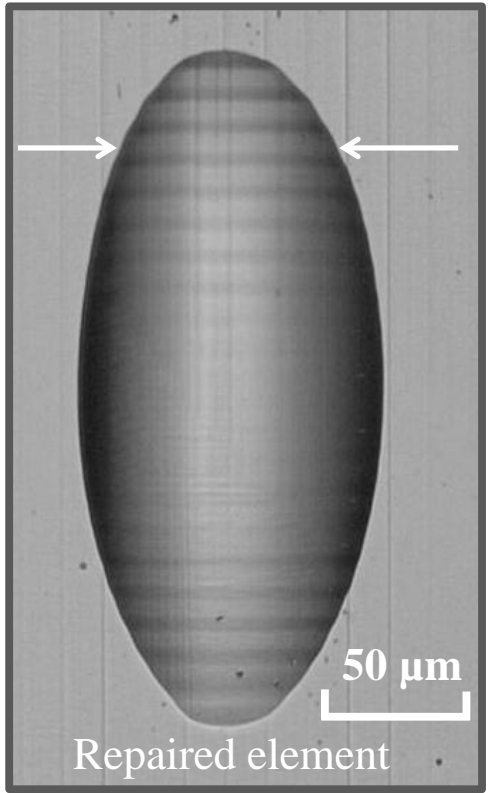

(a) Multi-time repair

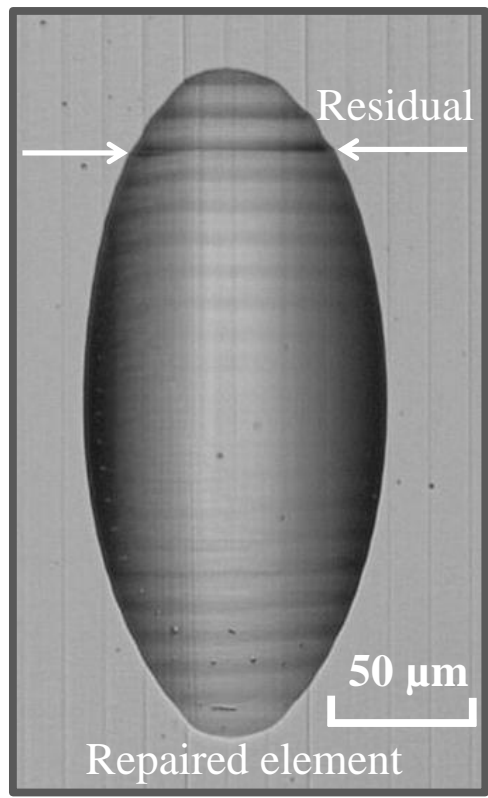

(b) One-time repair

Fig. 10. Optical microscopic images of the repaired results after (a) multi-time repair and (b) one-time repair. 


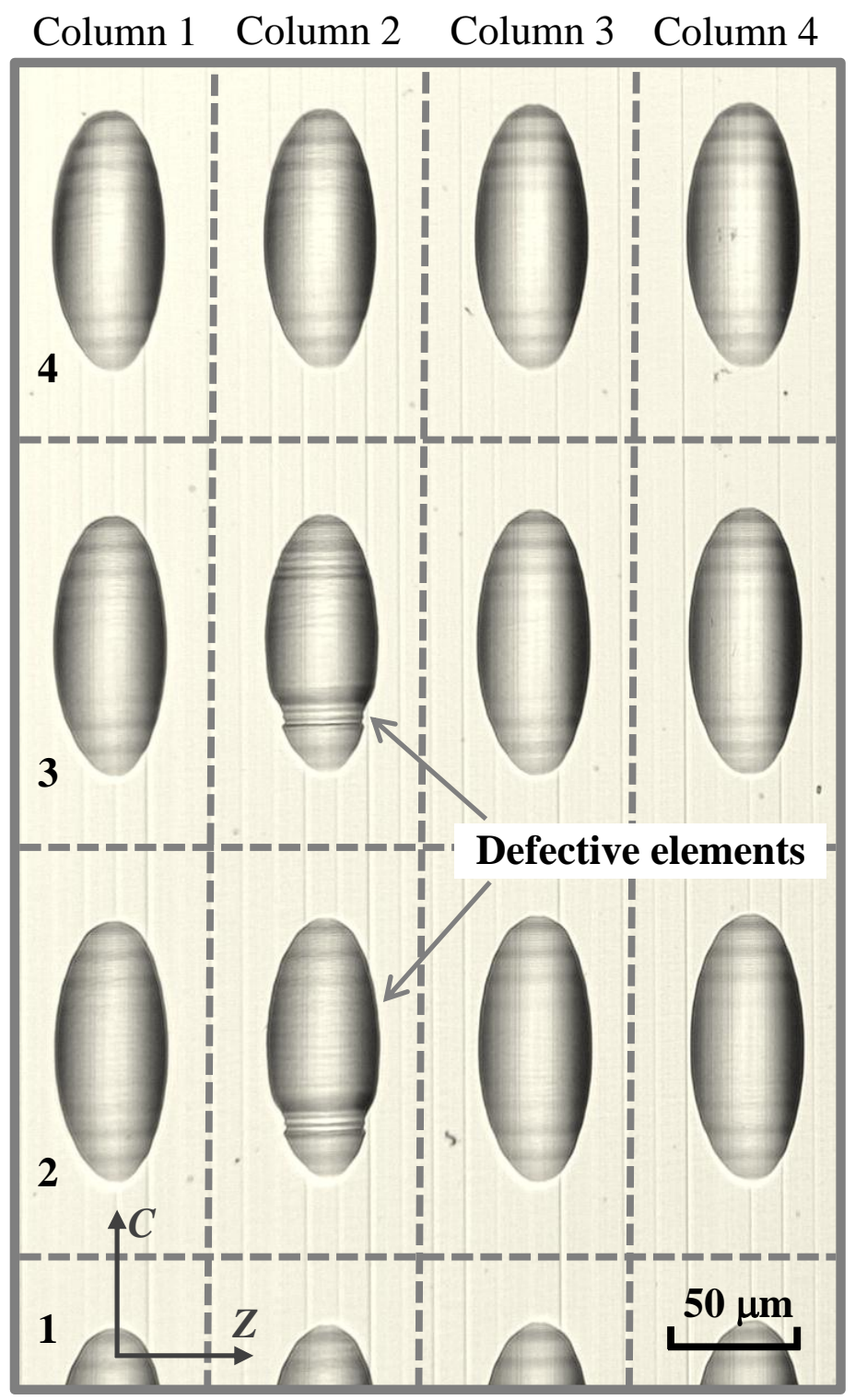

Fig. 11. Optical microscopic image of a part of the cut microstructure element array. 


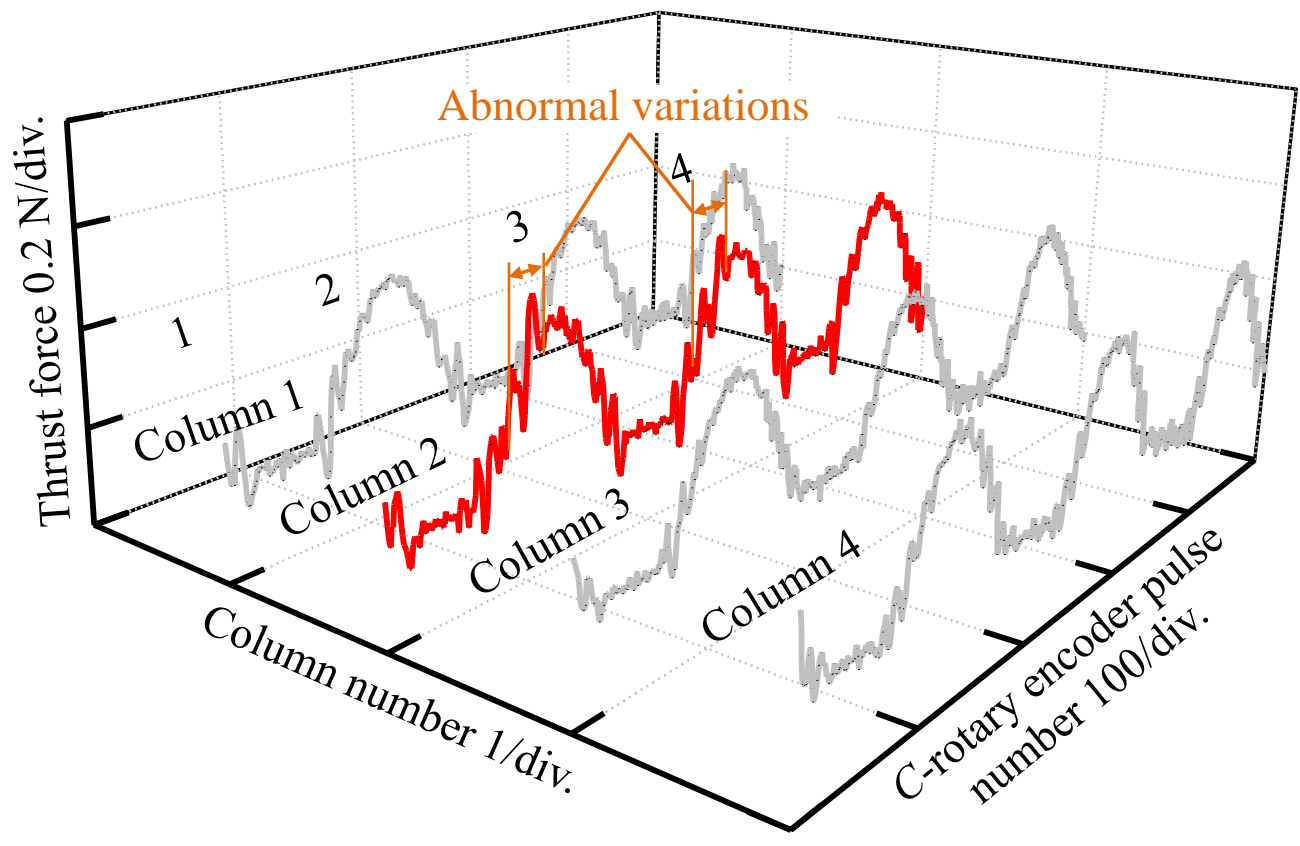

Fig. 12. A part of the in-process monitored thrust force map during the cutting of the microstructure element array. 


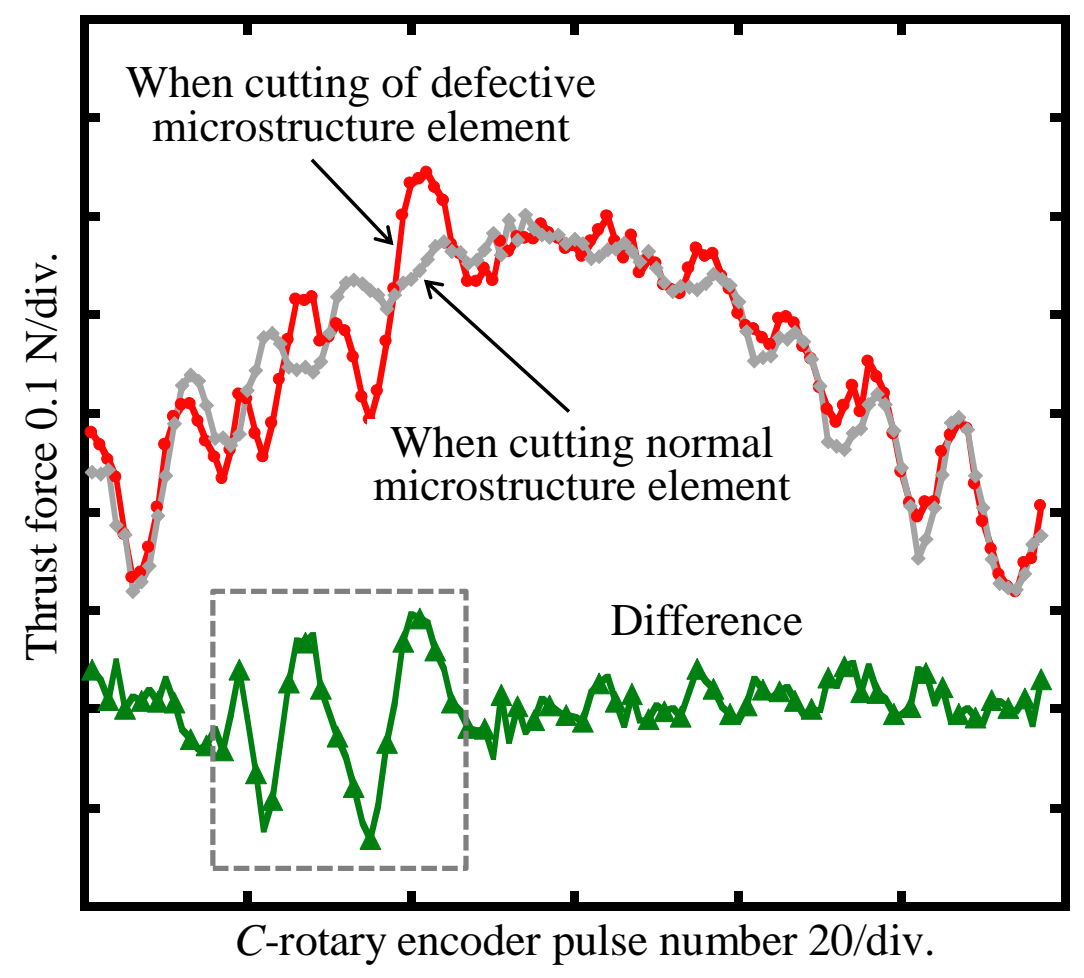

Fig. 13. Comparison of the thrust force during the fabrication of defective and normal microstructure elements. 


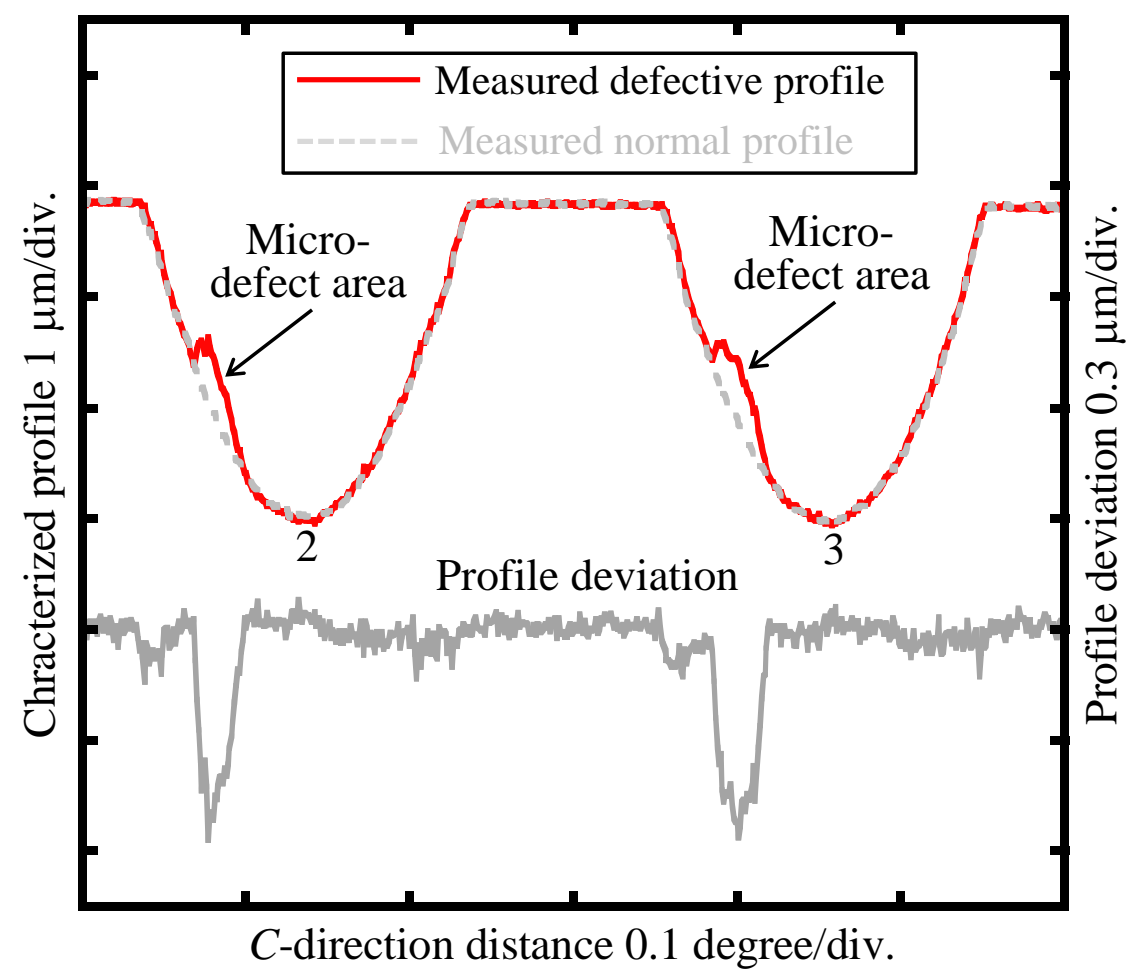

Fig. 14. Measured sectional profile of the defective microstructure elements compared with the measured profile of normal elements. 


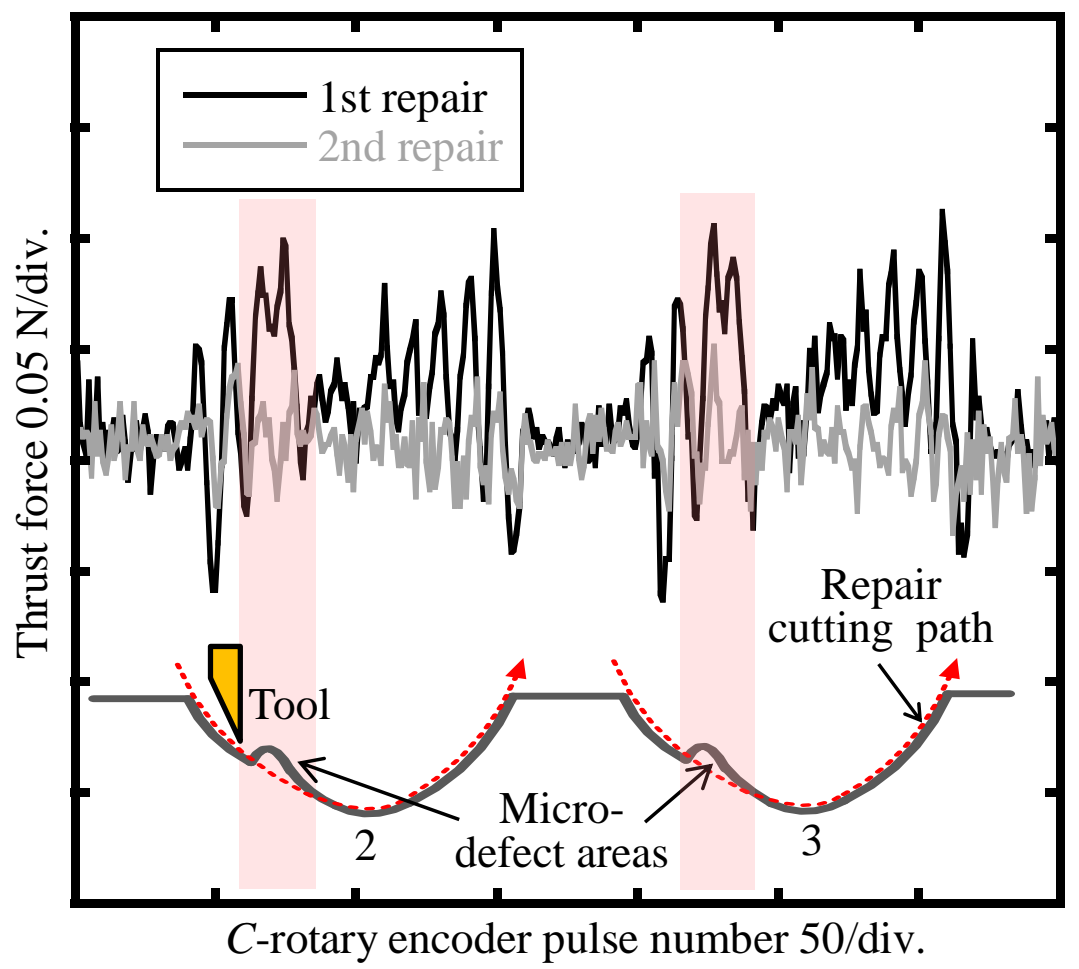

Fig. 15. Measured thrust force during the repair process. 


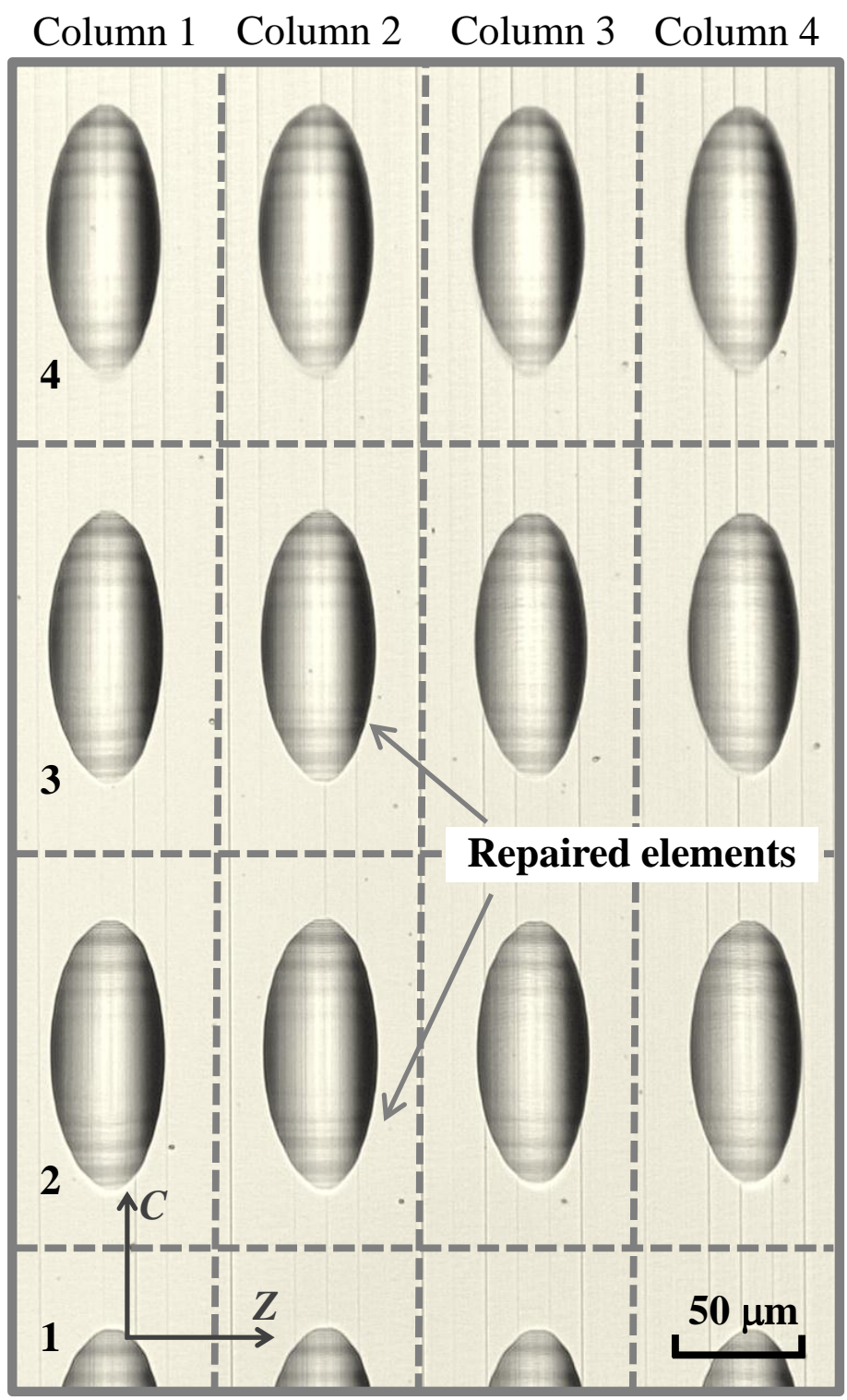

Fig. 16. Optical microscopic image of the microstructure element array after repair. 


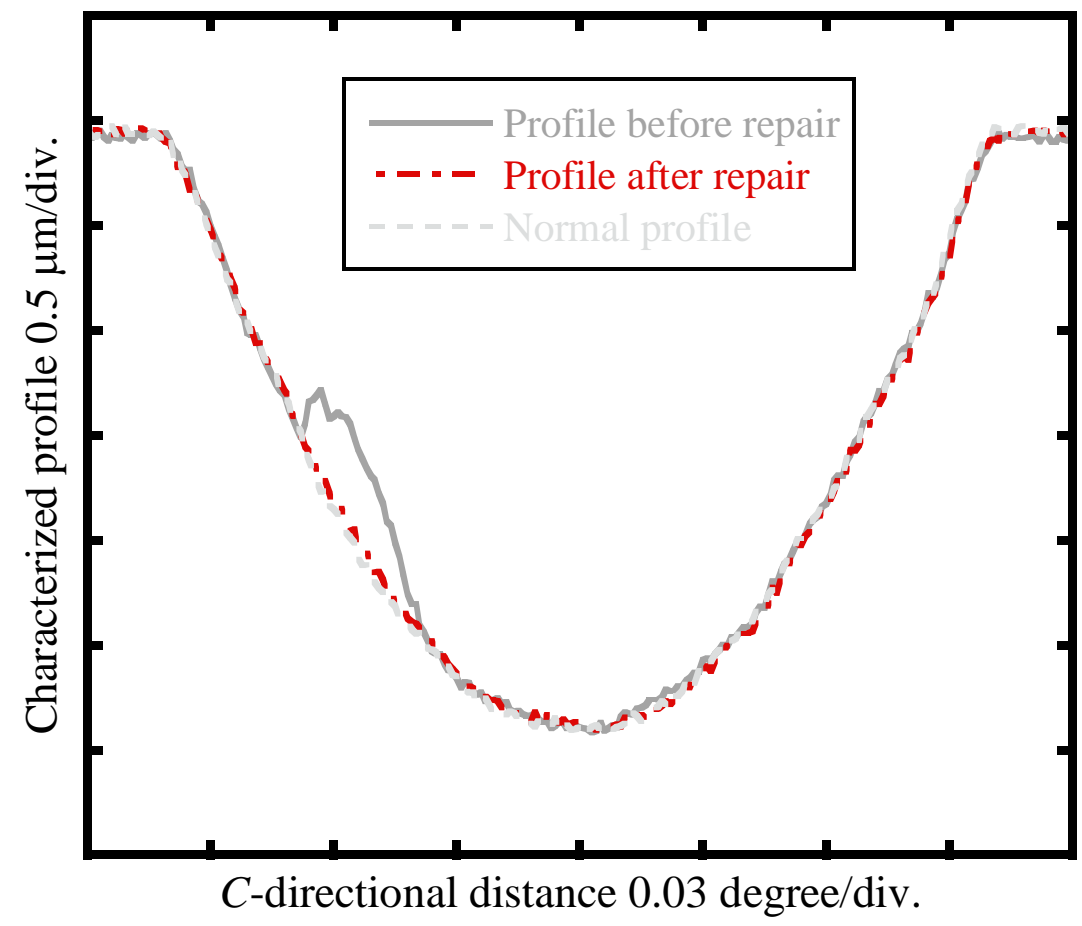

Fig. 17. Measured sectional profile of the defective microstructure element after repair. 


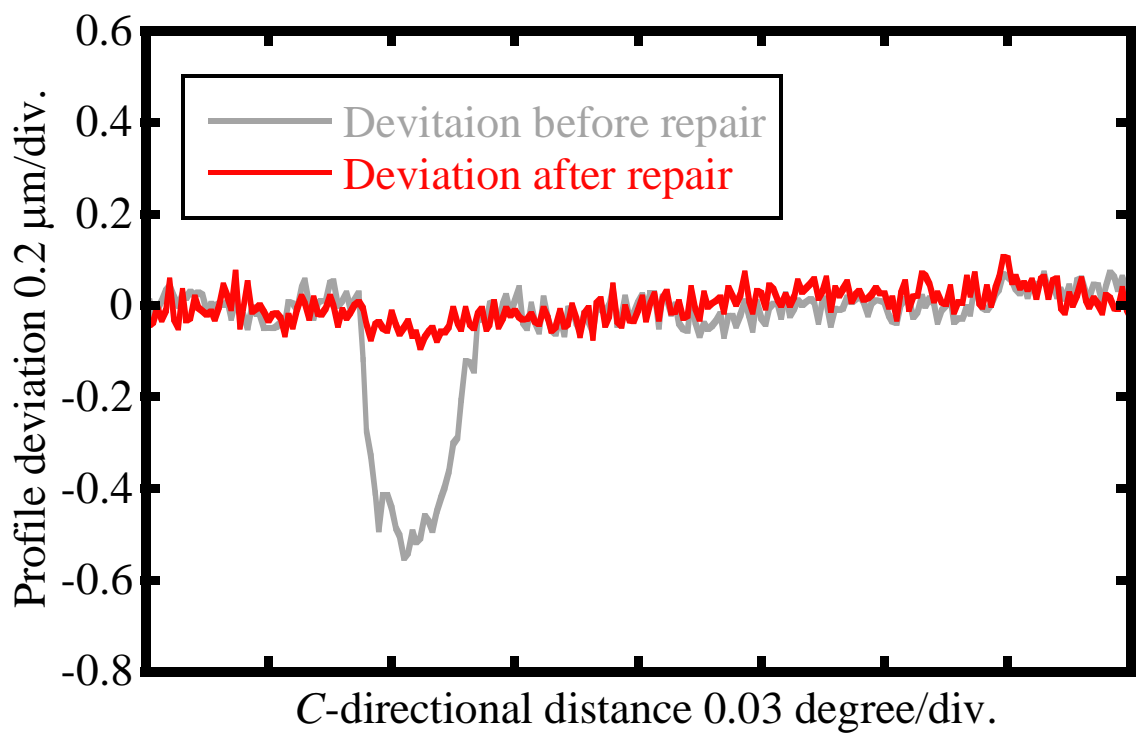

Fig. 18. Comparison of the measured profile deviation before and after repair. 